\title{
Respiratory Burst Oxidase and Three of Four Oxidase-related Polypeptides Are Associated with the Cytoskeleton of Human Neutrophils
}

\author{
Richard C. Woodman, Julie M. Ruedi, Algirdas J. Jesaitis," Naoki Okamura, Mark T. Quinn," \\ Robert M. Smith, John T. Curnutte, and Bernard M. Babior \\ Department of Molecular and Experimental Medicine, Research Institute of Scripps Clinic, La Jolla, California 92037; \\ and ${ }^{*}$ Department of Chemistry, Montana State University, Bozeman, Montana 59717
}

\begin{abstract}
Resting and phorbol-activated human neutrophils were separated by treatment with Triton $\mathrm{X}-100$ into detergent-extractable and cytoskeleton fractions. Respiratory burst oxidase activity was restricted entirely to the cytoskeleton. The cytoskeleton also contained $\approx 15 \%$ of the neutrophil cytochrome $b_{558}$, an oxidase-associated heme protein, as well as most of the oxidase-related cytosolic polypeptide $p 67^{\text {phox }}$. In contrast, the components of the oxidase-associated phosphoprotein family p47 $7^{\text {phox }}$ were found almost exclusively in the detergent extract, suggesting that $p 47^{\text {phox }}$ is needed for oxidase activation but not for $\mathrm{O}_{2}^{-}$production by the activated oxidase. Activation of the oxidase had no apparent effect on the distribution of any of these species between the cytoskeleton and the detergent extract. Our results support earlier studies implying that the cytoskeleton participates in an important way in regulating the activity of the $\mathrm{O}_{2}^{-}$-forming respiratory burst oxidase of neutrophils. (J. Clin. Invest. 1991. 87:1345-1351.) Key words: neutrophil • cytoskeleton • respiratory burst oxidase
\end{abstract}

\section{Introduction}

The exposure of neutrophils to appropriate stimuli activates a metabolic pathway known as the "respiratory burst" whose purpose is the generation of microbicidal oxidants through the partial reduction of oxygen (1). The key to this metabolic pathway is the respiratory burst oxidase, a membrane-bound enzyme that catalyzes the one-electron reduction of oxygen to $\mathrm{O}_{2}^{-}$ at the expense of NADPH: $\mathrm{O}_{2}+\mathrm{NADPH} \rightarrow \mathrm{O}_{2}^{-}+\mathrm{NADP}^{+}$ $+\mathrm{H}^{+}$. The respiratory burst oxidase is dormant in resting neutrophils, but acquires catalytic activity when the cells are incubated with any of a wide variety of stimuli. The $\mathrm{O}_{2}^{-}$produced by this oxidase is the precursor of the very complex mixture of

Dr. Woodman's present address is Department of Medicine, Foothills Hospital, Calgary, Alberta, Canada. Dr. Okamura's present address is Department of Physiological Chemistry, Hiroshima University School of Medicine, Hiroshima, Japan. Dr. Smith's present address is Department of Medicine, University of California at San Diego School of Medicine, San Diego, CA 92093.

Address reprint requests to Dr. Bernard M. Babior, Division of Biochemistry, Research Institute of Scripps Clinic, 10666 North Torrey Pines Road, La Jolla, CA 92037.

Received for publication 24 October 1988 and in revised form 29 November 1990.

J. Clin. Invest.

(c) The American Society for Clinical Investigation, Inc.

0021-9738/91/04/1345/07 \$2.00

Volume 87, April 1991, 1345-1351 microbicidal oxidants generated by activated neutrophils during the respiratory burst.

Recent observations have furnished strong indications that the respiratory burst oxidase and its activating apparatus may be associated in some manner with the neutrophil cytoskeleton, a series of filament networks that define the shape and organelle distribution of the neutrophil and are indispensable for its motor function. Inhibitor studies have suggested that the actin microfilament network in particular plays an important role in regulating the activity of the respiratory burst oxidase. The effect of several microfilament-disrupting agents, including the cytochalasins (2) and the Clostridium botulinum C2 iota toxin (3), on the production of $\mathrm{O}_{2}^{-}$in response to certain stimuli, most notably the $\mathrm{N}$-formylated chemotactic peptides, clearly implies some sort of relationship between the cytoskeleton and the respiratory burst oxidase. Jesaitis and his associates have published several studies suggesting that this relationship is mediated through effects of the cytoskeleton on the traffic of $\mathrm{N}$-formylated peptide receptors (2), but a more direct connection between the oxidase and the cytoskeleton was not ruled out. Recently, Nathan has found that the delayed but protracted respiratory burst elicited from surface-adherent neutrophils by exposure to tumor necrosis factor can be abolished by dihydrocytochalasin B (4), again implicating the cytoskeleton in the regulation of the respiratory burst.

We have now used more direct methods to examine the association between the respiratory burst oxidase and the neutrophil actin microfilament network. Our experiments were based on the results with microfilament-depolymerizing agents described above, as well as on earlier work with neutrophil phosphoproteins (5-9). Our findings provide further support for a relationship between the actin microfilament system and the respiratory burst oxidase, suggesting that the microfilaments are connected to the oxidase not only functionally, but physically as well.

\section{Methods}

Materials. ${ }^{32} \mathrm{P}$-labelled phosphoric acid (carrier free in $0.02 \mathrm{M} \mathrm{HCl}$ ) was obtained from ICN Radiochemicals, Div. Radiochemicals, Inc., Irvine, CA. Protease inhibitors (EDTA, diisopropyl fluorophosphate [DFP], ${ }^{1}$ leupeptin, and pepstatin), phorbol myristate acetate (PMA), mercaptoethanol, $N, N, N, N^{\prime}$-tetramethylethylene diamine, DNAse I (type II, bovine pancreas), dihydrocytochalasin $\mathrm{B}$, cytochrome $c$ (horse heart type VI), superoxide dismutase (bovine erythrocyte), dimethyl sulfoxide, prestained fumarase (used as a $48 \mathrm{~K}$ marker for the second dimension of two-dimensional gel electrophoresis) and Triton X-100 were purchased from Sigma Chemical Co., St. Louis, MO. Ampholines and Ficoll-Hypaque were obtained from Pharmacia Fine Chemicals, Pis-

1. Abbreviations used in this paper: CGD, chronic granulomatous disease; DFP, diisopropyl fluorophosphate. 
cataway, NJ, and LKB Instruments, Inc., Gaithersburg, MD. SDS acrylamide, $N, N^{\prime}$-methylenebisacrylamide, ammonium persulfate, Coomassie brilliant blue R-250, and agarose (ultrapure high grade DNA agarose) were obtained from Bio-Rad Laboratories, Richmond, CA, pI markers from Calbiochem-Behring Corp., San Diego, CA, and Ultrapure $^{\star}$ urea from Schwarz/Mann, Spring Valley, NY. Asolectin (Associated Concentrates, Woodside, NY), a preparation of mixed soybean phospholipids, was prepared for use by sonication to clarity ( 50 W, room temperature, argon atmosphere) at $2 \mathrm{mg} \mathrm{lipid/ml} \mathrm{in} \mathrm{Hanks'}$ balanced salts without $\mathrm{Ca}^{++}$and $\mathrm{Mg}^{++}$. Other materials were the best quality commercially available and were used without further purification.

Buffers. The names and compositions of the buffers referred to in the succeeding sections of Methods and elsewhere in the text are given in Table I.

Respiratory burst oxidase activity in neutrophil cytoskeletons and detergent extracts. Neutrophils were suspended in incubation buffer at a concentration of $10^{7}$ cells $/ \mathrm{ml} .4 \mathrm{ml}$ of this suspension was incubated at $37^{\circ} \mathrm{C}$ for $5 \mathrm{~min}$, then supplemented with $40 \mu \mathrm{l}$ PMA solution (20 $\mu \mathrm{g} / \mathrm{ml}$ in DMSO) and incubated for an additional $2 \mathrm{~min}$ at $37^{\circ} \mathrm{C}$ to activate the neutrophils, terminating the reaction by immersion in an ice slurry. The suspension was centrifuged at $100 \mathrm{~g}$ for $10 \mathrm{~min}$ at $4^{\circ} \mathrm{C}$, the supernatant discarded, and the cells (total $4 \times 10^{7}$ neutrophils) suspended in $2 \mathrm{ml}$ of Triton inhibitor buffer (10-12) and incubated at $0^{\circ} \mathrm{C}$ for $30 \mathrm{~min}$. Next, $0.3 \mathrm{ml}$ of the cell suspension was reserved for measuring total respiratory burst oxidase activity, while $0.1-\mathrm{ml}$ samples were placed in each of eight screw-cap Eppendorf tubes and centrifuged for $30 \mathrm{~s}$ at $4^{\circ} \mathrm{C}$. The cytoskeletons in one pair of tubes were immediately resuspended in their supernatants by repeated pipetting, while the detergent extracts from the other tubes were withdrawn and set aside. Cytoskeletons in a second pair of tubes were suspended in $0.1-\mathrm{ml}$ portions of Triton inhibitor buffer, and $0.1 \mathrm{ml}$ of detergent extract was placed in each of a third pair of tubes. Finally, isolated cytoskeletons in a fourth pair of tubes were resuspended in $0.1-\mathrm{ml}$ portions of detergent extract. Respiratory burst oxidase activity was assayed by adding superoxide dismutase $(0.1 \mathrm{mg})$ to one of each pair of tubes to serve as reference, then adding to each tube flavin adenine dinucleotide (FAD) (final concentration $1.0 \mu \mathrm{M})$, cytochrome $c(83 \mu \mathrm{M})$, asolectin solution $(0.6$ $\mathrm{ml})$, and NADPH (0.1 mM, added last) to a final vol of $1 \mathrm{ml}$, incubating the samples for $10 \mathrm{~min}$ at room temperature on a rocking platform, and finally adding superoxide dismutase to the second of each pair of tubes and measuring cytochrome $c$ reduction as described elsewhere (13).

Table I. Buffers

\begin{tabular}{|c|c|}
\hline Name & Composition \\
\hline Incubation buffer & 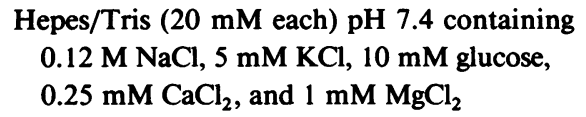 \\
\hline $\begin{array}{l}\text { Termination } \\
\text { buffer }\end{array}$ & $\begin{array}{l}\text { Hepes/Tris (20 mM each) pH } 7.4 \text { containing } \\
0.12 \mathrm{M} \mathrm{NaCl}, 5 \mathrm{mM} \mathrm{KCl} \text {, and } 10 \mathrm{mM} \text { glucose }\end{array}$ \\
\hline $\begin{array}{l}\text { Inhibitor buffer } \\
\text { (3) }\end{array}$ & $\begin{array}{l}\text { Termination buffer supplemented with protease } \\
\text { inhibitors consisting of } 0.5 \mathrm{mM} \text { DFP (added } \\
\text { as a } 10 \text {-mM solution in dry ethylene glycol) } \\
20 \mu \mathrm{M} \text { leupeptin, and } 18 \mu \mathrm{M} \text { pepstatin (final } \\
\text { concentrations) }\end{array}$ \\
\hline $\begin{array}{l}\text { Triton inhibitor } \\
\text { buffer }\end{array}$ & $\begin{array}{l}\text { Inhibitor buffer: } 5 \%(\mathrm{wt} / \mathrm{vol}) \text { aqueous Triton } \\
\mathrm{X}-100=4: 1(\mathrm{vol} / \mathrm{vol})\end{array}$ \\
\hline Lysis buffer & $\begin{array}{l}\text { Freshly prepared } 9.5 \mathrm{M} \text { urea containing } 2 \% \\
\text { (wt/vol) Nonidet } \mathrm{P}-40,1.6 \% \text { (vol/vol) } \mathrm{pH} 5-7 \\
\text { ampholines, } 0.4 \%(\mathrm{vol} / \mathrm{vol}) \mathrm{pH} 3.5-10 \\
\text { ampholines, and } 5 \%(\mathrm{vol} / \mathrm{vol}) \\
\text { mercaptoethanol }\end{array}$ \\
\hline Sonication buffer & Tris $(10 \mathrm{mM}) \mathrm{pH} 7.4$ containing $5 \mathrm{mM} \mathrm{MgCl}{ }_{2}$ \\
\hline
\end{tabular}

Assay of neutrophil cytoskeletons and detergent extracts for cytochrome $b_{s 5 g}$. Neutrophils $\left(10^{8}\right.$ cells in $\left.10 \mathrm{ml}\right)$ were prepared in incubation buffer and (where indicated) activated with PMA (final concentration $0.2 \mu \mathrm{g} / \mathrm{ml}$ ) exactly as described elsewhere (6). Incubations were terminated after $2 \mathrm{~min}$ with $10 \mathrm{ml}$ ice-cold termination buffer supplemented with $10 \mathrm{mM}$ EDTA. The cells were isolated by centrifugation $\left(110 \mathrm{~g}, 4^{\circ} \mathrm{C}, 10 \mathrm{~min}\right)$, suspended in $5 \mathrm{ml}$ inhibitor buffer containing 10 mM EDTA, incubated at least $20 \mathrm{~min}$ at $4^{\circ} \mathrm{C}$, and reisolated by centrifugation. Cytoskeletons were then prepared by suspending the cells in 5 $\mathrm{ml}$ Triton inhibitor buffer and extracting for $30 \mathrm{~min}$ on ice. A $1-\mathrm{ml}$ portion of the whole cell lysate was reserved for the determination of cytochrome $b_{558}$. Detergent extract and cytoskeleton were then separated by centrifugation of the remaining whole cell lysate $\left(15 \mathrm{~min}, 4^{\circ} \mathrm{C}\right.$, Eppendorf). Detergent extract left in the cytoskeleton as initially prepared was removed by suspending the cytoskeleton in $4 \mathrm{ml}$ Triton inhibitor buffer and centrifuging again. The supernatant from this second extraction (designated "residual extract") was reserved for assay of cytochrome $b_{558}$. The firm pellet of washed cytoskeleton was suspended by trituration for 5-15 min at room temperature in $1 \mathrm{ml}$ Triton inhibitor buffer containing $2 \mathrm{mg} / \mathrm{ml}$ DFP-treated DNAse (DNAse I in buffer containing $0.5 \mathrm{mM}$ DFP [added as $10 \mathrm{mM}$ DFP in dry ethylene glycol]) and $2 \mathrm{mM} \mathrm{CaCl}_{2}$ to depolymerize F-actin (14). The amount of cytochrome $b_{558}$ in each sample (i.e., whole neutrophil lysate, initial detergent extract, residual extract, and washed cytoskeleton) was determined by dithionite difference spectroscopy as described elsewhere (15), using a recording spectrophotometer (860; Kontron Elektronik $\mathrm{GmbH}$, Zurich, Switzerland) and measuring absorbances between 410 and $440 \mathrm{~nm}$ at $0.5-\mathrm{nm}$ intervals.

Analysis of protein phosphorylation in neutrophil cytoskeletons and detergent extracts. Neutrophils were prepared, loaded with ${ }^{32} \mathrm{P}_{\mathrm{i}}(0.4$ $\mathrm{mCi} / 10^{7}$ cells), and activated with PMA (final concentration $0.2 \mu \mathrm{g} / \mathrm{ml}$ ) exactly as described elsewhere (6). Incubations were terminated after 2 min (unless otherwise indicated) with $1 \mathrm{ml}$ ice-cold termination buffer supplemented with $10 \mathrm{mM}$ EDTA, and the cells isolated by centrifugation (Eppendorf microfuge [15,600 g], $10 \mathrm{~min}$ ). The neutrophils were then resuspended in $1 \mathrm{ml}$ inhibitor buffer containing $10 \mathrm{mM}$ EDTA, incubated at least $20 \mathrm{~min}$ at $0^{\circ} \mathrm{C}$, and reisolated by centrifugation. Cytoskeletons were then prepared by suspending neutrophils in Triton inhibitor buffer at a concentration of $2 \times 10^{7}$ cells $/ \mathrm{ml}$ and incubating at $0^{\circ} \mathrm{C}$ for $30 \mathrm{~min}$. The detergent extract was separated from the nonextractable cytoskeleton by centrifugation as described above. Proteins in the detergent extract were precipitated by the method of Wessel and Flüge (16), dried in air, and dissolved in $0.1 \mathrm{ml}$ lysis buffer. The cytoskeleton was washed once with $0.25 \mathrm{ml}$ Triton inhibitor buffer, suspended by sonication at $0^{\circ} \mathrm{C}$ (model W-220F; Heat Systems-Ultrasonics, Inc., Plainview, NY, microtip, using multiple brief pulses) in $25 \mu 1$ sonication buffer, then treated to hydrolyze DNA by incubating for 5 min at $37^{\circ} \mathrm{C}$ after adding $2 \mu \mathrm{l}$ DFP-treated DNAse. The suspended cytoskeleton was then dissolved by gentle warming after adding $25 \mathrm{mg}$ solid urea followed by $50 \mu \mathrm{l}$ lysis buffer. After centrifugation ( $1 \mathrm{~min}$, Eppendorf microfuge), the solutions of cytoskeletal and detergent-soluble proteins were subjected to two-dimensional gel electrophoresis as described elsewhere (6) except that $\mathrm{pH} 2-4$ ampholines were replaced by pH 5-7 ampholines. In preparing each gel, the entire quantity of cytoskeleton or extract solution was used as sample; all gels from a given experiment were subjected to autoradiography for the same length of time.

Immunoblotting. Immunoblots of $\mathrm{gp} 91^{\text {phox }}$ and $\mathrm{p} 22^{\text {phox }}$ were prepared by electrophoretic transfer of proteins from SDS-polyacrylamide $7-18 \%$ gradient gels to nitrocellulose as previously described $(17,18)$. The nitrocellulose transfers were incubated for at least $2 \mathrm{~h}$ in blocking buffer ( $10 \%$ goat serum, $3 \% \mathrm{BSA}, 0.5 \mathrm{M} \mathrm{NaCl}$, and $10 \mathrm{mM}$ Hepes, $\mathrm{pH}$ 7.4) and then probed for $3 \mathrm{~h}$ with 1/1,000 dilutions of affinity-purified polyclonal rabbit anti-p22 2 phox or a polyclonal antibody raised in rabbits against a peptide corresponding to a portion of the $\mathrm{gp} 91^{\text {phox }}$ polypeptide chain in Dulbecco's PBS containing 3\% normal goat serum, $1 \%$ BSA, and $0.2 \%$ Tween 20 . The blots were then rinsed with wash buffer $(0.25 \mathrm{M} \mathrm{NaCl}, 0.2 \%$ Tween $20,10 \mathrm{mM}$ Hepes, $\mathrm{pH}$ 7.4); incubated for 1 
h with $1 \mu \mathrm{g} / \mathrm{ml}$ alkaline phosphatase conjugated goat anti-rabbit IgG (Bio-Rad) in Dulbecco's PBS containing 3\% goat serum, 1\% BSA, and $0.2 \%$ Tween 20; washed again; and developed using the Bio-Rad alkaline phosphatase conjugation substrate kit according to the manufacturer's directions. The stained blots were scanned using a soft laser densitometer (Zeineh, Fullerton, CA), and the data from six separate experiments averaged to accurately quantitate the relative distribution of cytochrome. (Blotting conditions were designed for optimal blocking of nonspecific proteins, but several bands were present on the gp9 $1^{\text {phox }}$ blot that were not eliminated by competition with excess synthetic peptide under conditions that eliminated the gp $91^{\text {phox }}$ band [data not shown]).

The cytosolic oxidase components $\mathrm{p} 47^{\text {phox }}$ and $\mathrm{p} 67^{\text {phox }}$ were also located by immunoblotting. For this purpose, antibodies were raised against the peptides $\mathrm{C}\left[{ }^{14} \mathrm{C}\right]$ FSTKRKLASAV and $\left[{ }^{14} \mathrm{C}\right]$ FTDLESTR$\mathrm{REV}$, the $10 \mathrm{COOH}$-terminal residues of which are identical to the $\mathrm{COOH}$-terminal decapeptides of $\mathrm{p} 47^{\text {phox }}$ and $\mathrm{p} 67^{\text {phox }}$, respectively. Both peptides were coupled to rabbit serum albumin and also to ovalbumin (Cappel Laboratories, Cochranville, PA) using standard techniques (19), and the conjugates were used to raise polyclonal antisera in rabbits (20). The resulting antisera were screened for reactivity with the oxidase components by immunoblotting against normal neutrophil cytosol, and for specificity by immunoblotting against cytosols from patients with chronic granulomatous disease (CGD) whose neutrophils lacked either $\mathrm{p} 47^{\text {phox }}$ or $\mathrm{p} 67^{\text {phox }}$ (data not shown). For electrophoresis, cytoskeletons were dissolved in $25 \mu \mathrm{l}$ inhibitor buffer, digested for 5 min at $37^{\circ} \mathrm{C}$ with DFP-treated DNAse $(1 \mathrm{mg} / \mathrm{ml})$, then supplemented with $25 \mu 12 \times$ sample buffer, while detergent extract proteins were precipitated as described (16) and dissolved in $25 \mu$ l inhibitor buffer plus $25 \mu 12 \times$ sample buffer. Protein solutions were then applied to $10 \%$ polyacrylamide gels and subjected to electrophoresis as described by Laemmli (21). The separated proteins were transferred to nitrocellulose at $50 \mathrm{~V}$ for $2 \mathrm{~h}$ at $4^{\circ} \mathrm{C}$. The nitrocellulose blots were blocked for $1 \mathrm{~h}$ with Blotto (22), incubated overnight with antibody $(1 / 10,000$ in Blotto) at $4^{\circ} \mathrm{C}$, then washed five times with Blotto. Visualization was accomplished by incubating the blots at room temperature for $3 \mathrm{~h}$ with alkaline phosphatase conjugated to goat anti-rabbit $\mathrm{F}\left(\mathrm{ab}^{\prime}\right)_{2}$, washing five times with Blotto, and developing the color with the Bio-Rad alkaline phosphatase conjugation substrate kit as described above.

Protein concentrations in cytoskeleton and detergent extracts. Protein concentrations were determined by the Bradford method (23) using a kit purchased from Bio-Rad. Concentrations of protein in detergent extracts and cytoskeleton were $153.7 \pm 5.1$ and $116.3 \pm 3.8 \mu \mathrm{g} / 10^{7}$ cells, respectively $(n=6)$.

\section{Results}

Both the respiratory burst oxidase and cytochrome $b_{558}$ are associated with the neutrophil cytoskeleton. Earlier evidence supporting a relationship between the neutrophil cytoskeleton and the respiratory burst oxidase depended on the demonstration that oxidase activity in whole cells was altered by agents known to inhibit the formation of actin microfilaments. We sought to obtain more direct evidence for such a relationship by measuring respiratory burst oxidase activity in cytoskeleton preparations obtained from PMA-activated human neutrophils. For our studies, cytoskeleton was prepared by extracting the cells with nonionic detergents using techniques similar to those employed in other laboratories $(10-12)$. We found that the treatment of whole activated neutrophils with Triton X-100 brought most of the proteins into solution, but left behind an insoluble residue of detergent-resistant cytoskeleton. By twodimensional gel electrophoresis, this insoluble residue was found to contain three major components; a protein that from its prominence and its location on the gel is probably actin, and two basic proteins, one that migrated at $M_{\mathrm{r}} \approx 60 \mathrm{~K}$ and the other at $M_{\mathrm{r}} \approx 90 \mathrm{~K}$, together with a large number of minor components at low concentration (Fig. 1). The composition of the cytoskeleton fraction from our experiments was similar to that reported by Yassin et al. (11), except that they observed only one major basic component, which migrated at $M_{\mathrm{r}}$ $\approx 60 \mathrm{~K}$.

Neutrophils treated with PMA are known to make large quantities of $\mathrm{O}_{2}^{-}$through the activation of the respiratory burst oxidase. Table II shows the distribution of the oxidase between the cytoskeleton and soluble fractions of PMA-treated neutrophils extracted with Triton X-100. The results indicate that when the cytoskeleton fraction was separated from the detergent-solubilized material by centrifugation, $>95 \%$ of the detectable $\mathrm{O}_{2}^{-}$-forming activity remained with the cytoskeleton. Even if it is assumed that the loss in oxidase activity that occurred during the separation procedure (compare row 1 with row 2 plus row 3 of Table II) was sustained entirely by a (hypothetical) detergent-soluble oxidase pool, cytoskeleton oxidase still would represent a third of the total oxidase activity found in the original Triton-solubilized preparation (Table II, row 2). It appears therefore that much, and probably most, of the $\mathrm{O}_{2}^{-}$forming activity in PMA-activated neutrophils is associated with the cytoskeleton.

Closely associated with the respiratory burst oxidase is a heme protein known as cytochrome $b_{558}$ that is present only in phagocytes (1) and B lymphocytes $(18,24)$ and is missing in two of the four currently recognized types of CGD, an inherited condition caused by a heterogeneous group of molecular abnormalities affecting the respiratory burst oxidase or its activating

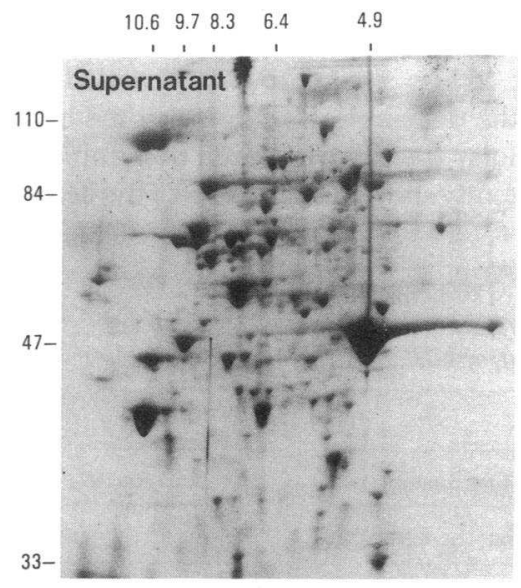

Figure 1. Composition of the detergent-resistant (cytoskeleton) and detergent-extractable fractions from phorbolactivated human neutrophils as determined by two-dimensional gel electrophoresis. Ten million $\left(10^{7}\right)$ neutrophils were used for this experiment. The preparation and extraction of the neutrophils and the electrophoresis of the extractable and cytoskeleton fractions were carried out as described in Methods. The proteins were visualized with Coomassie blue. 
Table II. Distribution of Respiratory Burst Oxidase between the Cytoskeleton and the Detergent-soluble Extract of Activated Human Neutrophils

\begin{tabular}{lccc}
\hline & \multicolumn{2}{c}{$\mathrm{O}_{2}^{-}$production } \\
\cline { 2 - 3 } \multicolumn{1}{c}{ Material } & Experiment 1 & Experiment 2 & Recovery \\
\cline { 2 - 3 } & \multicolumn{3}{c}{ nmol/10 min $/ 2 \times 10^{6}$ cell } \\
equivalent & $\% *$ \\
Triton-treated cells & 10.6 & 11.7 & $(100)$ \\
Cytoskeleton & 2.9 & 4.1 & 31.4 \\
Detergent extract & 0.1 & 0.1 & 0.8 \\
Cytoskeleton + detergent & & & 37.2 \\
extract & 3.7 & 4.6 & \\
\hline
\end{tabular}

Experiments were carried out as described in Methods using two different neutrophil preparations. The controls for these experiments (row 1) are the Triton-treated cells that were centrifuged and immediately resuspended (see text). This procedure caused the samples to lose $50.1 \%$ (Experiment 1 ) and $39.7 \%$ (Experiment 2) of their original $\mathrm{O}_{2}^{-}$-forming activity as measured in uncentrifuged samples, emphasizing the lability of the respiratory burst oxidase in the buffers employed for the preparation of cytoskeletons. ${ }^{*}$ Average.

apparatus (25). We have found that this cytochrome too is associated with the neutrophil cytoskeleton. This association was demonstrated both spectrophotometrically (Table III) and immunologically (Fig. 2), the latter showing that the association involved both the $\alpha-(22-\mathrm{kD})$ and $\beta-(91-\mathrm{kD})$ subunits of the cytochrome. In contrast to the respiratory burst oxidase, however, only $\sim 15 \%$ of the cytochrome was associated with the cytoskeleton. Somewhat surprisingly, this percentage did not change with the state of activation of the cells. It is of interest that the value of $15 \%$ is similar to that obtained in earlier studies in which the distribution of cytochrome $b_{558}$ among neutrophil subcellular fractions has been determined. Those studies have consistently shown that $\sim 85 \%$ of the heme protein is found in specific granules, which are devoid of oxidase activity, while the remaining $15 \%$ is found in plasma membrane fractions, which contain the membrane-associated components of the respiratory burst oxidase (15).

Lack of association of the phosphorylated forms of $p 47^{\text {phox }}$ with the cytoskeleton. In prior investigations, we and others have identified a family of closely related (6) $47 \mathrm{~K}$ phosphoproteins whose states of phosphorylation were shown to be intimately connected with the activation of the respiratory burst oxidase $(6,26-28)$. Because of $(a)$ the connection between $47 \mathrm{~K}$ protein phosphorylation and oxidase activation; $(b)$ the finding that the oxidase is associated with the cytoskeleton (see above); and $(c)$ prior work showing that some neutrophil phosphoproteins are situated in the cytoskeleton $(8,9)$, we felt that it would be of interest to examine the relationship between the oxidaserelated $47 \mathrm{~K}$ phosphoprotein family and the neutrophil cytoskeleton. We therefore loaded neutrophils with ${ }^{32} \mathrm{P}_{\mathrm{i}}$, activated them with PMA, then prepared extracts and cytoskeleton fractions that were analyzed for phosphoprotein composition by two-dimensional gel electrophoresis followed by autoradiography. The results showed a PMA-dependent increase in the labelling of four components of the $\mathrm{p} 47^{\text {phox }}$ family: $\mathrm{p} 47^{\text {phox }} / 6.8$, $\mathrm{p} 47^{\text {phox }} / 7.3, \mathrm{p} 47^{\text {phox }} / 7.8$, and $\mathrm{p} 47^{\text {phox }} / 8.6$ (the members of the $\mathrm{p} 47^{\text {phox }}$ family are designated by terminology based on their $M_{\mathrm{r}}$ and $\mathrm{pI}$ values [6]) (Fig. 3, $A, C$ [arrows]). These p47 ${ }^{\text {phox }}$ components were present exclusively in the detergent-soluble extract (Fig. 3, $A-D$ ). Their distribution was not altered by incubating the cells for $10 \mathrm{~min}$ at $37^{\circ}$ with $10 \mu \mathrm{M}$ dihydrocytochalasin $\mathrm{B}$ before adding the activating agent (data not shown). The cytoskeleton too contained a group of $M_{\mathrm{r}} \approx 47 \mathrm{~K}$ phosphoproteins with $\mathrm{pI}$ values in the neutral range, but these were not members of the p47 ${ }^{\text {phox }}$ family: their labelling did not increase with activation, and they were present in $\mathrm{p} 47^{\text {phox }}$ deficient cytoskeletons (Fig. 3, $E-J)(6,7,26,29)$.

Relationship between the cytoskeleton and the cytosolic oxidase components $p 47^{\text {phox }}$ and $p 67^{\text {phox }}$ as evaluated by immunoblotting. Confirmation that the cytoskeleton was essentially
Table III. Distribution of Cytochrome $b_{558}$ between the Cytoskeleton and the Detergent-soluble Extract of Resting and Activated Human Neutrophils

\begin{tabular}{|c|c|c|c|c|}
\hline \multirow[b]{3}{*}{ Sample } & \multicolumn{4}{|c|}{ Cytochrome $b_{558}$} \\
\hline & \multicolumn{2}{|c|}{ Experiment 1} & \multicolumn{2}{|c|}{ Experiment 2} \\
\hline & Resting & Activated & Resting & Activated \\
\hline & \multicolumn{4}{|c|}{ pmol $/ 10^{7}$ cell equivalent } \\
\hline \multicolumn{4}{|l|}{ Whole neutrophil } & 79.2 \\
\hline Initial extract & 84.9 & 75.0 & 75.5 & 82.1 \\
\hline Residual extract & ND & ND & ND & 0.9 \\
\hline Cytoskeleton & 11.7 & 12.6 & 10.2 & 16.0 \\
\hline & \multicolumn{4}{|c|}{ Percentage of total } \\
\hline Cytoskeleton & 12.1 & 14.3 & 11.9 & 16.3 \\
\hline
\end{tabular}

Experiments were conducted as described in Methods using two different neutrophil preparations. Total recoveries of cytochrome $b_{558}$ in the subcellular fractions averaged $111 \%$ and $131 \%$ for resting and activated cells, respectively. ND, not detected.

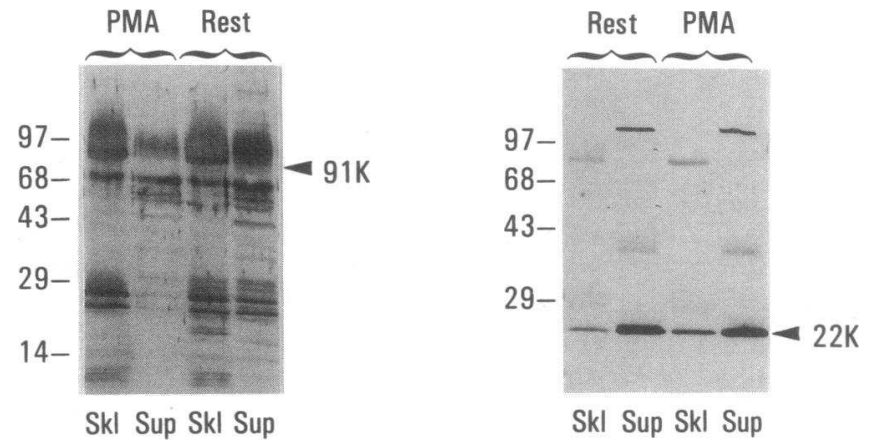

Figure 2. Association of the $91 \mathrm{~K}$ (left) and $22 \mathrm{~K}$ (right) subunits of cytochrome $\mathrm{b}_{558}$ with the neutrophil cytoskeleton as determined by immunoblotting. Each track contained $10^{7}$ cell equivalent of cytoskeleton $(s k l)$ or detergent extract (sup) from resting (rest) or PMAactivated $(P M A)$ normal human neutrophils. Fractions were prepared and immunoblotting was performed as described in Methods. Similar results were obtained in a second experiment using neutrophils from a different subject. The proportions of cytochrome $b_{558}$ associated with the cytoskeletons from resting and activated neutrophils were $10.2 \pm 2.8$ and $16.0 \pm 3.0 \%($ mean $\pm \mathrm{SD})$, respectively, as determined from scans of the autoradiograms of the $22 \mathrm{~K}$ subunits (Zeineh 10/2D laser scanner). 

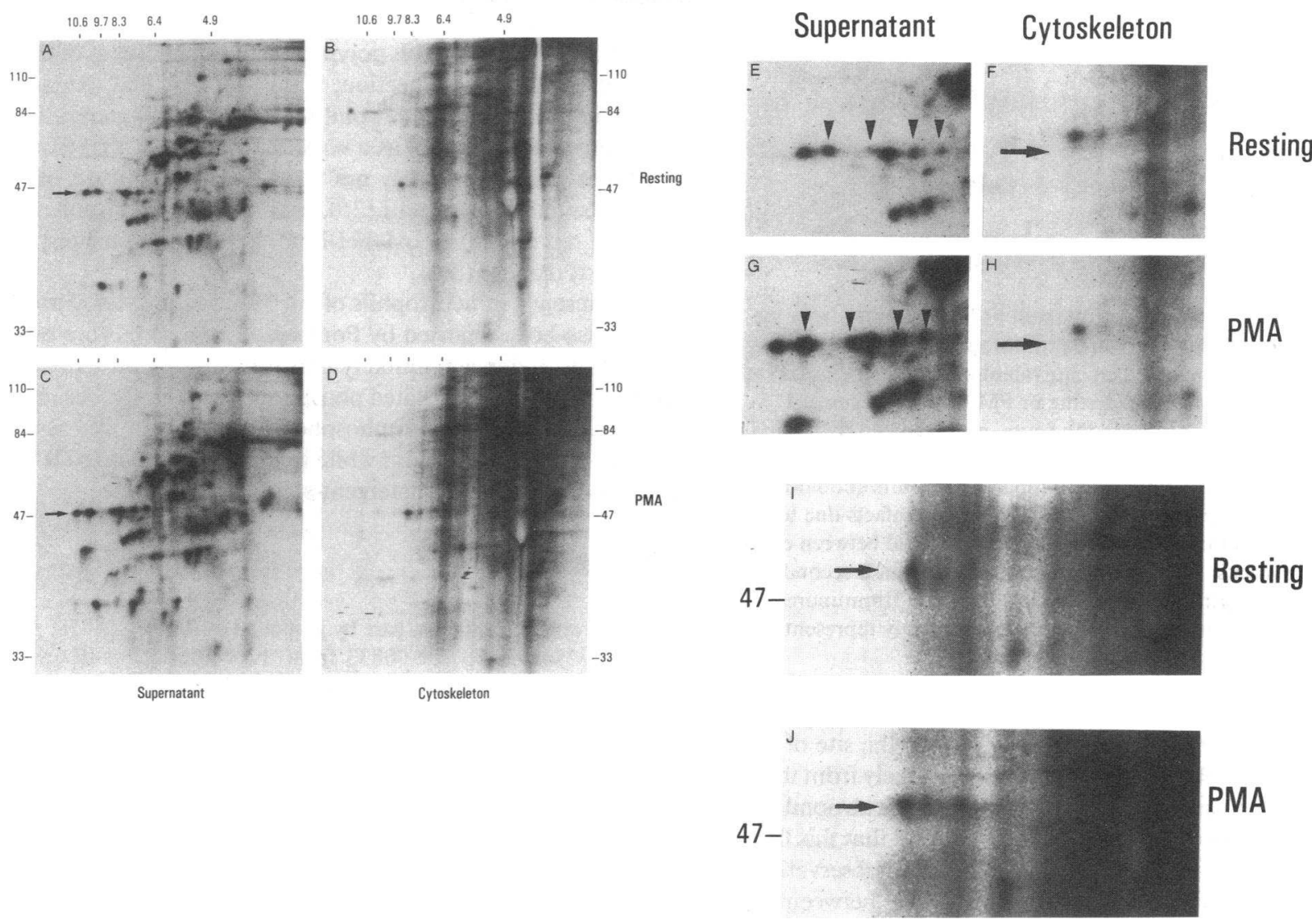

Figure 3. The phosphorylated $\mathrm{p} 47^{\text {phox }}$ components of the respiratory burst oxidase in normal ${ }^{32} \mathrm{P}_{\mathrm{i}}$-loaded human neutrophils are restricted to the detergent-extractable fractions. $(A-D)$ autoradiograms of complete two-dimensional gels of cytoskeletal and detergent-soluble proteins from ${ }^{32} \mathrm{P}_{\mathrm{i}}$-loaded neutrophils. The ${ }^{32} \mathrm{P}$-labelled $\mathrm{p} 47^{\text {phox }}$ family members in the detergent-extractable fractions (supernatant) are indicated by the arrows. $(E-H)$, details of the areas showing the $\mathrm{p} 47^{\text {phox }}$ family. (Arrowheads) Locations of the $\mathrm{p} 47^{\text {phox }}$ family members in the detergent-extractable fractions. (Arrow) Corresponding regions in the cytoskeletal fractions. (I-J) Cytoskeletal fractions from resting and activated neutrophils from a p47 $7^{\text {phox }}$-deficient individual showing the same $\approx 47 \mathrm{~K}$ phosphorylated proteins present in cytoskeletons from normal subjects.

The experiment was carried out as described in the text. Similar results were obtained in a second experiment using neutrophils from a different normal subject.

free of $\mathrm{p} 47^{\text {phox }}$ was obtained by immunoblotting. In preparations obtained from both resting and activated neutrophils, immunoreactive $\mathrm{p} 47^{\text {phox }}$ was restricted almost entirely to the detergent extract (Fig. 4); comparison with standards (shown in the two right-hand tracks of the blot) suggests that the cytoskeleton contained $<5 \%$ of the total amount of $\mathrm{p} 47^{\text {phox }}$ in the cell. These observations further indicate that to the extent that the cells contained unphosphorylated $\mathrm{p} 47^{\text {phox }}$, this unphosphorylated material was also separate from the cytoskeleton.

A $67 \mathrm{~K}$ protein, $\mathrm{p} 67^{\text {phox }}$, has been identified as a fourth polypeptide component of the respiratory burst oxidase (30). Immunoblots with an antibody that recognizes this polypeptide have shown that in both resting and activated neutrophils, almost all the detectable $\mathrm{p} 67^{\text {phox }}$ is associated with the cytoskeleton (Fig. 5). The fraction of $\mathrm{p} 67^{\text {phox }}$ associated with the cytoskeleton does not seem to depend in a major way on the state of activation of the cell.

\section{Discussion}

As discussed in the introduction, the finding that the activity of the respiratory burst oxidase is related to the neutrophil cytoskeleton has been anticipated by earlier work from other groups. ${ }^{2}$ We have now found that the respiratory burst oxidase appears to be attached to the cytoskeleton, as are three of the four oxidase polypeptides discovered through studies with neutrophils from patients with $\operatorname{CGD}(31,32)$. These findings constitute perhaps the most straightforward evidence to date in favor of a role for the cytoskeleton in the respiratory burst. The interaction between the oxidase and the cytoskeleton is probably the factor that allows the oxidase to be activated locally rather than globally in response to particulate stimuli (33). Other functions of the cytoskeleton-oxidase interaction, including a possible role in priming and deactivation, remain to be determined.

These experiments show that in resting neutrophils $\sim 15 \%$ of the cytochrome $b_{558}$ is found in the cytoskeleton. This figure does not change during the activation of the oxidase, indicating that oxidase activation is not accompanied by the transfer of

2. While this manuscript was under review, Quinn et al. reported the association of oxidase activity and cytochrome $b_{558}$ with the membrane cytoskeleton of human neutrophils (31). These investigators found that all the oxidase activity was associated with the membrane cytoskeleton, and that cytochrome $b_{558}$ was distributed evenly between the membrane cytoskeleton and the detergent extract. 

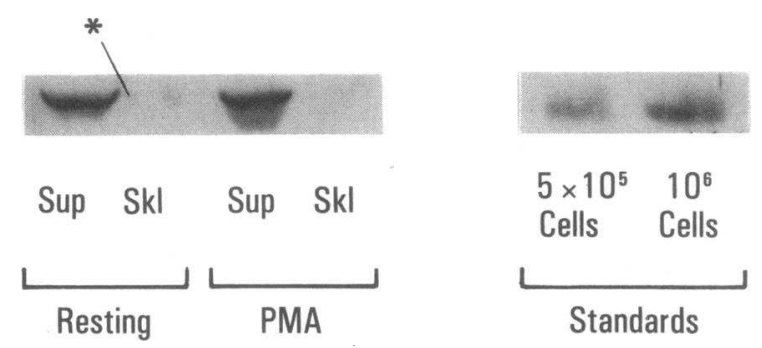

Figure 4. The cytosolic oxidase component $\mathrm{p} 47^{\text {phox }}$ is absent from the neutrophil cytoskeleton as determined by immunoblotting. The four left-hand tracks contained $10^{7}$ cell equivalent of detergent extract $($ sup) or cytoskeleton ( $s k l)$ from resting or PMA-activated normal human neutrophils as indicated in the figure, while the two right-hand tracks contained $5 \times 10^{5}$ and $10^{6}$ cell equivalents of resting detergent extract, respectively. Fractions were prepared and immunoblotting was performed as described in Methods. To avoid artifacts due to leakage from adjacent tracks, an empty track was placed between each pair of sample tracks. Similar results were obtained in a second experiment using neutrophils from a different donor. ${ }^{*}$ Immunoreactive $\mathrm{p} 47^{\text {phox }}$ in an empty track. This material probably represents a leak from the far left track.

cytochrome $b_{558}$ from other parts of the cell to the site of the active enzyme (i.e., the cytoskeleton). It seems likely from these observations that only a small fraction of the neutrophil cytochrome $b_{558}$ is associated with the oxidase, and that this fraction is already in place in the resting cell. These observations and the known distribution of cytochrome $b_{558}$ between the plasma membrane $(\approx 15 \%)$ and the specific granules $(\approx 85 \%)$ suggest that it is the cytochrome in the plasma membranes that is related to the oxidase. These considerations raise a question as to what the function of the specific granule cytochrome $b_{558}$ might be.

The foregoing results also indicate that whereas the $\mathrm{O}_{2}^{-}$forming activity from activated neutrophils is restricted almost entirely to the cytoskeleton, the $\mathrm{p} 47^{\text {phox }}$ family is found exclusively in the detergent-soluble supernatant. $\mathrm{O}_{2}^{-}$production in the cytoskeleton therefore takes place in the absence of $\mathrm{p} 47^{\text {phox }}$ It appears that $\mathrm{p} 47^{\text {phox }}$, while necessary for the activation of the respiratory burst oxidase, is not a component of the enzyme
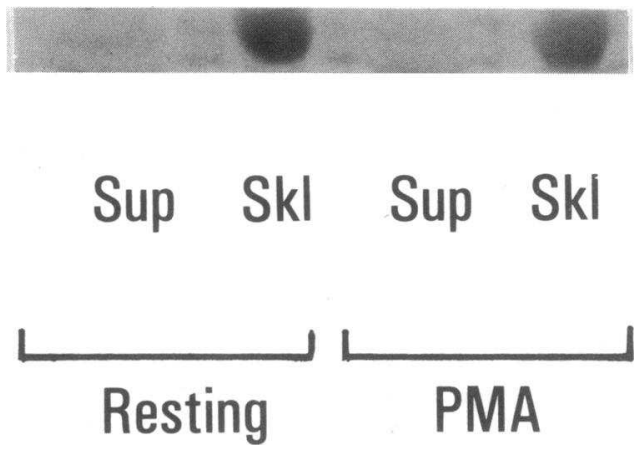

Figure 5. Association of $\mathrm{p} 67^{\text {phox }}$ with the neutrophil cytoskeleton as determined by immunoblotting. Each track contained $5 \times 10^{6}$ cell equivalent of detergent extract (sup) or cytoskeleton $(s k l)$ from resting or PMA-activated normal human neutrophils. Fractions were prepared and immunoblotting was performed as described in Methods. Similar results were obtained in a second experiment using neutrophils from a different donor. per se. Conversely, the cytoskeletal location of $\mathrm{p} 67^{\text {phox }}$ is compatible with the idea that this polypeptide is a constituent of the oxidase itself. In this connection, it is of interest that oxidase purified from activated neutrophil membranes (34) contained a $67 \mathrm{~K}$ component, as well as $\mathrm{a} \approx 48 \mathrm{~K}$ component that from the present work is probably not $\mathrm{p} 47^{\text {phox }}$ but may be an oxidase-associated flavoprotein (35), and $\mathrm{a} \approx 32 \mathrm{~K}$ component that could represent the NADPH-binding subunit of the respiratory burst oxidase (36).

The presence in neutrophils of a $47 \mathrm{~K}$ phosphorylated protein has also been reported by Pontremoli et al. (8). From our observations, it appears unlikely that this phosphoprotein is a member of the oxidase-related phosphoprotein family, because in their experiments the unphosphorylated protein was associated with the cytoskeleton, while in our experiments $\mathrm{p} 47^{\text {phox }}$ was always found in the detergent-soluble fraction.

\section{Acknowledgments}

This work was supported in part by grants AI-24227, AI-24838, AI26711, AI-28479, and RR-00833 from the National Institutes of Health, and a Grant-in-Aid from the American Heart Association with funds contributed in part by the California affiliate. J. T. Curnutte and A. J. Jesaitis are Established Investigators of the American Heart Association, and M. T. Quinn is a Fellow of the Arthritis Association.

\section{References}

1. Curnutte, J. T., and B. M. Babior. 1987. Chronic granulomatous disease. In Advances in Human Genetics. H. Harris and K. Hirschhorn, editors. Plenum Publishing Corp., New York. 229-297.

2. Jesaitis, A. J., J. O. Tolley, and R. A. Allen. 1986. Receptor-cytoskeleton interactions and membrane traffic may regulate chemoattractant-induced superoxide production in human granulocytes. J. Biol. Chem. 261:13662-13669.

3. Al-Mohanna, F. A., I. Ohishi, and M. B. Hallett. 1987. Botulinum C2 toxin potentiates activation of the neutrophil oxidase. Further evidence of a role for actin polymerization. FEBS (Fed. Eur. Biochem. Soc.) Lett. 219:40-44.

4. Nathan, C. F. 1987. Neutrophil activation on biological surfaces. Massive secretion of hydrogen peroxide in response to products of macrophages and lymphocytes. J. Clin. Invest. 80:1550-1560.

5. Hayakawa, T., K. Suzuki, S. Suzuki, P. C. Andrews, and B. M. Babior. 1986. A possible role for protein phosphorylation in the activation of the respiratory burst in human neutrophils. Evidence from studies with cells from patients with chronic granulomatous disease. J. Biol. Chem. 261:9109-9115.

6. Okamura, N., J. T. Curnutte, R. L. Roberts, and B. M. Babior. 1988. Relationship of protein phosphorylation to the activation of the respiratory burst oxidase in human neutrophils. Defects in the phosphorylation of a group of closely related $48 \mathrm{~K}$ proteins in two forms of chronic granulomatous disease. $J$. Biol. Chem. 263:6777-6782.

7. Okamura, N., S. E. Malawista, R. L. Roberts, H. Rosen, H. D. Ochs, B. M. Babior, and J. T. Curnutte. 1988. Phosphorylation of the oxidase-related 48K phosphoprotein family in the unusual autosomal cytochrome-negative and Xlinked cytochrome-positive types of chronic granulomatous disease. Blood. 72:811-816

8. Pontremoli, S., E. Melloni, M. Michetti, B. Sparatore, F. Salamino, O. Sacco, and B. L. Horecker. 1987. Phosphorylation and proteolytic modification of specific cytoskeletal proteins in human neutrophils stimulated by phorbol 12-myristate 13-acetate. Proc. Natl. Acad. Sci. USA. 84:3604-3608.

9. Pontremoli, S., E. Melloni, M. Michetti, B. Sparatore, F. Salamino, O. Sacco, and B. L. Horecker. 1987. Phosphorylation by protein kinase C of a 20$\mathrm{kDa}$ cytoskeletal polypeptide enhances its susceptibility to digestion by calpain. Proc. Natl. Acad. Sci. USA. 84:398-401.

10. Osborn, M., and K. Weber. 1977. The detergent-resistant cytoskeleton of tissue culture cells includes the nucleus and the microfilament bundles. Exp. Cell. Res. 106:339-349.

11. Yassin, R., J. Shefcyk, J. R. White, W. Tao, M. Volpi, T. F. P. Molski, P. H. Naccache, M. B. Feinstein, and R. I. Sha'afi. 1985. Effects of chemotactic factors and other agents on the amounts of actin and a 65,000-mol-wt protein associated with the cytoskeleton of rabbit and human neutrophils. J. Cell Biol. 101:182-188.

12. Hornbeck, P., and W. E. Paul. 1986. Anti-immunoglobulin and phorbol 
ester induce phosphorylation of proteins associated with the plasma membrane and cytoskeleton in murine B lymphocytes. J. Biol. Chem. 261:14817-14824.

13. Markert, M., P. C. Andrews, and B. M. Babior. 1984. Measurement of $\mathrm{O}_{2}^{-}$ production by human neutrophils; the preparation and assay of NADPH oxidasecontaining particles from human neutrophils. Methods Enzymol. 105:358-365.

14. Fox, J. E. B. 1985. Identification of actin-binding protein as the protein linking the membrane skeleton to glycoproteins on platelet plasma membranes. J. Biol. Chem. 260:11970-11977.

15. Curnutte, J. T., R. Kuver, R. and P. J. Scott. 1987. Activation of neutrophil NADPH oxidase in a cell-free system. Partial purification of components and characterization of the activation process. J. Biol. Chem. 262:5563-5569.

16. Wessel, D., and U. I. Flügge. 1985. A method for the quantitative recovery of protein in dilute solution in the presence of detergents and lipids. Anal. Biochem. 138:141-143.

17. Towbin, H., T. Staehlin, and J. Gordon. 1979. Electrophoretic transfer of proteins from polyacrylamide gels to nitrocellulose sheets: procedure and some applications. Proc. Natl. Acad. Sci. USA. 76:4350-4354.

18. Parkos, C. A., R. A. Allen, C. G. Cochrane, and A. J. Jesaitis. 1987. Purified cytochrome $b$ from human granulocyte plasma membrane is comprised of two polypeptides with relative molecular weights of 91,000 and 22,000. J. Clin. Invest. 80:732-742.

19. Doolittle, R. F. 1986. Of URFS and ORFS. A Primer on How To Analyze Derived Amino Acid Sequences. University Science Books, Mill Valley, CA

20. Catty, D. 1988. Antibodies. Vol. 1. IRL Press Ltd., Oxford.

21. Cleveland, D. W., S. G. Fischer, M. W. Kirschner, and U. K. Laemmli. 1977. Peptide mapping by limited proteolysis in sodium dodecyl sulfate and analysis by gel electrophoresis. J. Biol. Chem. 252:1102-1106.

22. Schwarz, H. P., M. J. Heeb, J. D. Wencel-Drake, and J. H. Griffin. 1985. Identification and quantitation of protein $\mathrm{S}$ in human platelets. Blood. 66:14521455 .

23. Bradford, M. M. 1976. A rapid and sensitive method for the quantitation of microgram quantities of protein utilizing the principle of protein-dye binding. Anal. Biochem. 72:248-254.

24. Maly, F.-E., M. Nakamura, J.-F. Gauchat, A. Urwyler, C. Walker, C. A. Dahinden, A. R. Cross, O. T. G. Jones, and A. L. de Weck. 1989. Superoxide-dependent nitroblue tetrazolium reduction and expression of cytochrome $b-245$ components by human tonsillar B lymphocytes and B cell lines. J. Immunol. 142:1260-1267.
25. Curnutte, J. T. 1988. Classification of chronic granulomatous disease Hematol./Oncol. Clin. North. Am. 2:241-252.

26. Segal, A. W., P. G. Heyworth, S. Cockcroft, and M. M. Barrowman. 1985. Stimulated neutrophils from patients with autosomal recessive chronic granulomatous disease fail to phosphorylate a $M_{r} 44,000$ protein. Nature (Lond.) 316:547-549.

27. Volpp, B. D., W. M. Nauseef, and R. A. Clark. 1988. Two cytosolic neutrophil oxidase components absent in autosomal chronic granulomatous disease. Science (Wash. DC). 242:1295-1297.

28. Nunoi, H., D. Rotrosen, J. I. Gallin, and H. L. Malech. 1988. Two forms of autosomal chronic granulomatous disease lack distinct neutrophil cytosol factors. Science (Wash. DC). 242:1298-1301.

29. Kramer, I. J. M., A. J. Verhoeven, R. L. van der Bend, R. S. Weening, and D. Roos. 1988. Purified protein kinase $C$ phosphorylates a $47 \mathrm{kDa}$ protein in control neutrophil cytoplasts but not in neutrophil cytoplasts from patients with the autosomal form of chronic granulomatous disease. J. Biol. Chem. 263:23522357

30. Leto, T. L., K. J. Lomax, B. D. Volpp, H. Nunoi, J. M. G. Sechler, W. M. Nauseef, R. A. Clark, J. I. Gallin, and H. L. Malech. 1990. Cloning of a 67-kD neutrophil oxidase factor with similarity to a noncatalytic region of $\mathrm{p}^{60^{\mathrm{c}-s r c}}$. Science (Wash. DC). 248:727-730.

31. Quinn, M. T. C. A. Parkos, and A. J. Jesaitis. 1989. The lateral organization of components of the membrane skeleton and superoxide generation in the plasma membrane of stimulated human neutrophils. Biochim. Biophys. Acta. 987:83-94.

32. Babior, B. M., and R. C. Woodman. 1990. Chronic granulomatous disease. Semin. Hematol. 27:247-259.

33. Ohno, Y.-I., K.-I. Hirai, T. Kanoh, H. Uchino, and K. Ogawa. 1982. Subcellular localization of $\mathrm{H}_{2} \mathrm{O}_{2}$ production in human neutrophils stimulated with particles and an effect of cytochalasin-B on the cells. Blood. 60:253-260.

34. Glass, G. A., D. M. DeLisle, P. DeTogni, T. G. Gabig, B. H. Magee, M. Markert, and B. M. Babior. 1986. The respiratory burst oxidase of human neutrophils. Further studies of the purified enzyme. J. Biol. Chem. 261:13247-13251.

35. Yea, C. M., A. R. Cross, and O. T. G. Jones. 1990. Purification and some properties of the $45 \mathrm{kDa}$ diphenylene iodonium-binding flavoprotein of neutrophil NADPH oxidase. Biochem. J. 265:95-100.

36. Babior, B. M., T. Umei, J. T. Curnutte, and R. M. Smith. 1990. The NADPH-binding protein of the respiratory burst oxidase may be a $32 \mathrm{~K}$ protein that is labelled by NADPH dialdehyde. Blood. 76:176a. 